\title{
Seçici Lazer Sinterleme Tabanlı 3D Yazıcının Tasarımı
}

\author{
Fatma Nazlı Özsolak ${ }^{1 *}$, Bülent Kaya ${ }^{2}$ \\ ${ }^{1 *}$ Erciyes Universitesi, Mühendislik Fakültesi, Endüstriyel Tasarım Mühendisliği, Kayseri, Türkiye, (ORCID: 0000-0001-6312-8675), fnsari@erciyes.edu.tr \\ ${ }^{2}$ Erciyes Universitesi, Mühendislik Fakültesi, Endüstriyel Tasarım Mühendisliği, Kayseri, Türkiye, (ORCID: 0000-0002-7943-8683), bulentkaya@erciyes.edu.tr
}

(1st International Conference on Applied Engineering and Natural Sciences ICAENS 2021, November 1-3, 2021)

(DOI: 10.31590/ejosat.1011235)

ATIF/REFERENCE: Özsolak, F.N. \& Kaya, B. (2021). Seçici Lazer Sinterleme Tabanlı 3D Yazıcının Tasarımı.European Journal of Science and Technology, (28), 785-789.

\section{$\ddot{O} \mathbf{z}$}

Geleneksel imalat yöntemlerinden farklı olarak, 3D baskı teknolojisi, son yıllarda nesnelerin ve parçaların üretiminde etkili bir şekilde kullanılmaya başlanmıştır. Günümüzde 3D yazıcılar ile hızlı ve verimli bir şekilde tasarlanan parçaların prototip veya nihai ürün imalatını gerçekleştirmek mümkündür. Hatta bazı durumlarda başka yöntemlerle imal edilemeyecek son derece karmaşık geometriler 3D baskı ile üretilebilmektedir (Berman 2012), (Wong ve Hernandez 2012).

Çalışma kapsamında Seçici Lazer Sinterleme (SLS) 3D yazıcı tasarımı gerçekleştirilecektir. Seçici Lazer Sinterleme (SLS) veya seçici lazer ergitme (SLM) tabanlı bir 3D metal baskı tekniği geliştirilmesinde ilk ve en önemli safha, bir lazer kaynağından elde edilen enerjinin belli zaman ve durumlarda, hedef metal tozu üzerine belirlenen konumlara düşürülmesidir. Tasarlanacak olan SLS tabanlı 3D yazıcı sistemindeki bağımsız birimlerin (lazer, optik, lensler, kontrol yazılımı gibi) kişiselleştirilmiş yazılım ile entegrasyonu hedeflenmektedir.

Anahtar Kelimeler: Eklemeli İmalat, Seçici Lazer Sinterleme, 3D Metal Yazıcı, Toz Yatak Tipleri, Toz Serme Sistemleri.

\section{Design of Selective Laser Sintering 3D Printer}

\begin{abstract}
Unlike traditional manufacturing methods, 3D printing technology has been used effectively in the production of objects and parts in recent years. Today, with $3 \mathrm{D}$ printers, it is possible to produce prototypes or final products of designed parts quickly and efficiently. In some cases, extremely complex geometries that cannot be produced by other methods can be produced with 3D printing ( Berman 2012), (Wong ve Hernandez 2012).

Within the scope of this study, Selective Laser Sintering (SLS) 3D printer design will be realized. The first and most important step in the development of a 3D metal printing technique based on Selective Laser Sintering (SLS) or Selective Laser Melting (SLM) is to reduce the energy obtained from a laser source to specified positions on the target metal powder at certain times and situations. It is aimed to integrate the independent units (such as laser, optics, lenses, control software) in the SLS-based 3D printer system to be designed with personalized software.
\end{abstract}

Keywords: Additive Manufacturing, Selective Laser Sintering, 3D Metal printer, Powder Bed Types, Powder Laying Systems.

\footnotetext{
*Corresponding Author: fnsari@,erciyes.edu.tr
} 


\section{Giriş}

Lazer tabanlı üç boyutlu yazıcılar ile ilgili literatür incelendiğinde eklemeli imalat ile ilgili simülasyon ve modelleme çalışmaları tespit edilmiştir. Eklemeli imalat yöntemleri içerisinde küçük-hassas parçaların üretiminde ekonomik, hızlı ve az adetli üretim için bir çözüm avantajına sahip SLS tabanlı 3D yazıcıların geliştirilmesi önem arz etmektedir.

3D baskı veya eklemeli imalat adı verilen bu teknolojinin ISO/ASTM 52900:2015 göre, "herhangi bir malzemeyi bir bask1 kafası, nozul veya başka bir baskı teknolojisi vasıtasıyla yığarak, bir objenin üretimini gerçekleştirme faaliyetidir" şeklinde tanımlanmıştır (Conner 2014). 1980' li yıllarda başlayan ve hızlı prototipleme (Rapid Prototyping-RP) olarak adlandirılan bu imalat metodu artık günümüzde, baskı süresi ve nihai ürün çıktısındaki fonksiyonelliğin geliştirilmesi neticesinde yakalanan başarılar nedeniyle eklemeli imalat (Additive ManufacturingAM) olarak anılan yeni ve kabul gören bir üretim metodunu işaret etmektedir.

Buna göre, tıpkı kâğıt üzerine baskıda mürekkep kullanılması gibi, 3D yazıcılar katman katman, termoplastiklerden metallere, cam, seramik, kâğıt ve hatta kompozit içerikli çok çeşitli malzemeleri kullanarak 3D fiziksel objeleri basmaktadır. Kullanılan baskı malzemeleri ise uygulanan eklemeli imalat baskı yöntemlerine göre değişiklik arz eder. Buna göre eklemeli imalat için kullanılan malzemeler, siv1, toz ve katı (filament veya levha) halde bulunurlar ve kullanılan malzemeye göre eklemeli imalat proseslerini sinıflandirırlar.

ASTM katmanlı imalatı (AM); malzeme çıkarımı imalat yöntemlerinin aksine 3 boyutlu parçaları üretmek için malzemenin katman katman eklenmesi sonucu oluşturulduğu yöntem olarak tanımlamaktadır. Eş anlamlıları ise eklemeli imalat, ekleme prosesi, eklemeli katmanlı üretim ve serbest form üretimidir (Herderick 2011). Bu tanım içeriğinde metaller, seramikler, polimerler, kompozitler ve biyolojik sistemlerin olduğum geniş bir alanda uygulanabilir. Her ne kadar 20 yılı aşkın bir süredir bu teknik üzerinde çalışmalar yapılsa da daha yeni yeni günümüzde ticari bir öneme sahip imalat yöntemi olmaya başlamıştır.

Seçici Lazer Sinterleme (SLS) veya Eritme (SLM) tabanlı metal 3D yazıcı geliştirilmesi sürecinde, birçok destek sistemine ve sistem tasarımına ihtiyaç duyulmaktadır. SLS teknolojisinde üretilen parçalarda destek malzemesi kullanılmadığından imal edilen parçaların temizlenmesi için gereken süre de ortadan kalkar.

\section{Materyal ve Metot}

Toz yatak tipli SLS veya SLM, lazer eklemeli imalat yöntemleri için hız ve hassasiyet ve dolayısıyla bu parametrelere bağımlı olan artan verimlilik şu an bilinen haliyle ancak galvo tarayıcı sistemler ile sağlanmaktadır. Dolayısıyla galvo lazer tarayıc1 ve bununla entegre optik sistemler toz yataklı eklemeli imalat sistemlerin kalbini oluşturur. Galvo tarayıcılar, entegre aynası ile çok hızlı olarak belirlenen bir kesiti (slice) tarayarak lazeri tozla birleştirir. Sistemin düşük kütlesi yüksek ivmeli konumlamalarda bile yüksek kararlılık ve dolayısıyla yüksek bir konumlama hassasiyeti sunmaktadır. Çeşitli kontrol zorlukları olsa da bu durum geleneksel servo motor / bilyalı mil konfigürasyonundan çok daha hızlı ve titreşimsiz hareket sağlar. Hatta günümüzde bu hız, polygon lazer tarayıcılar (Dong 2009) ile kat kat daha da arttırılmaya çalışılmaktadır.

Buna göre, lazer kaynağından çıkarak, toz üzerinde hedef X ve Y konumlamalarını sağlayacak olan 2 eksen lazer tarama modülüne odaklanır. Burada hassas galvo servo motorlarına entegre aynalara düşürülen lazer, toz üzerinde seçili bölgelere yansıtılır. Böylelikle yüksek enerjiye sahip lazer, belirlenen koordinatlarda tozun seçili bölgelerine düşürülerek, burada belirli bölgelerin eritilerek, katılaşmasına neden olur. Bir katmanda işi biten lazerin çalışması için, bir toz sıyırıcı mekanizması bu katmanın üzerine belirli bir yükseklikte toz serer ve lazer bu yeni toz katmanı üzerinde çalışmasına devam eder.

Esasen toz yataklı metal eklemeli imalat sistemleri göreceli olarak basit bir mantıkla 3D baskı yapılmasına imkan tanır. Buna göre 3 temel aşamanın gerçekleşmesi ile SLS veya SLM olarak adlandırılan eklemeli imalat prosesi gerçekleşir:

1)3D CAD, STL verinin işlenmesi ve katman kalınlığına göre dilimlenmesi (slicing)

2) $\mathrm{Bu}$ dilimlenmiş bir dizi 2D kesitin, yeterince güçlü ve odaklanan bir enerji ile metal tozu üzerine markalanması

3) Her bir kesit için belirgin bir katman kalınlığında tozun serilmesi (toz beslemesi ve toz yatağı hareketinin sağlanması) ve böylelikle tüm kesitlerin toz üzerinde markalanıncaya kadar döngünün devam ettirilmesi.

\subsection{Toz Yatak Sistemi}

Şekil 1 Toz Yatak Sisteminin temel çalışma prensibini gösteren bir şemadır. $\mathrm{Bu}$ sistem tozun çalışma alanı boyunca belirgin bölgelerinde (seçici) eritilmesine dayanır. Enerji kaynağ (elektron 1şını veya lazer 1şını), istenilen şeklin elde edilmesi için birleşmenin gerçekleşeceği yüzeyde toz malzemeyi eritmek ya da sinterlemek üzere programlanmıştır.

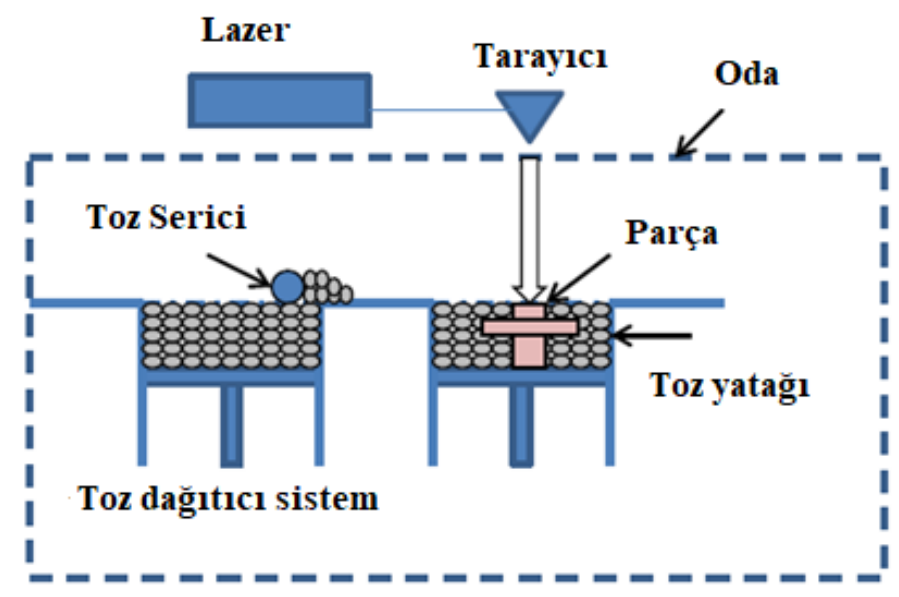

Şekil 1. AM Toz Yatak Sisteminin Jenerik Gösterimi (Kathuria 1999)

Yöntem iki boyutlu olup her defasında bir katmana uygulanarak katmanlar arasında bağlantı oluşturup üç boyutlu geometrinin oluşumu sağlanmaktadır. Katman kalınlığı $50 \mu \mathrm{m}$ veya arzu edilen parça özelliklerine bağlı olarak daha az olacak şekilde uygulanabilir. Bu yöntemin avantajı yüksek çözünürlük özelliklerinin elde edilmesi, kompleks iç geçişlerin 
sağlanabilmesi, boyutsal hassasiyet ve homojen tane yapısı ile yüksek mukavemetli parçalardır.

\subsubsection{Toz Besleme Sistemi}

Toz besleme sisteminin genel çalışma prensibi Şekil 2'de verilmiştir. $\mathrm{Bu}$ sistemlerin hacimsel parça baskı kapasitesi genellikle toz yatak sistemlerinden nazaran daha büyüktür. Ayrica hibrid, yani hem lazer katmanlı hem de talaşlı imalat üretimini de barındırabilir.

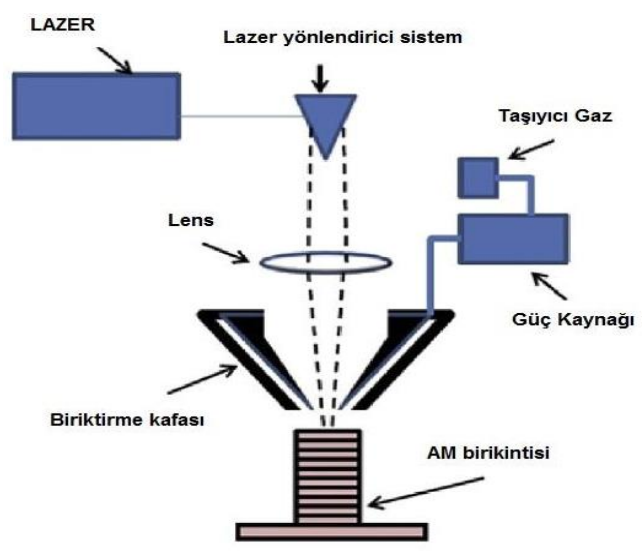

Sekil 2. AM Toz Besleme Sisteminin Gösterimi (Kathuria 1999)

Toz yataklı, Seçici Lazer Sinterleme (SLS) veya Seçici Lazer Eritme (SLM) teknolojisi ne olursa olsun, lazer kaynağının belirgin koordinatlar üzerine düşürülmesinde galvo tarayıcılar (galvo scanner) kullanılır.

Lazer eklemeli imalat yöntemleri için hız ve hassasiyet ve dolayısıyla bu parametrelere bağımlı olan artan verimlilik şu an bilinen haliyle ancak galvo tarayııı sistemler ile sağlanmaktadır. Dolayısıyla galvo lazer tarayıc1 ve bununla entegre optik sistemler toz yataklı eklemeli imalat sistemlerin kalbini oluşturur. Galvo tarayıcılar, entegre aynası ile çok hızlı olarak belirlenen bir katman kesitini (slice) tarayarak lazeri metal tozun üzerine düşürür.

Sistemin düşük kütlesi yüksek ivmeli konumlamalarda bile yüksek kararlılık ve dolayısıyla yüksek bir konumlama hassasiyeti sunmaktadır. Çeşitli kontrol zorlukları olsa da bu durum geleneksel servo motor / bilyalı mil konfigürasyonundan çok daha hızlı ve titreşimsiz hareket sağlar. Hatta günümüzde bu hız, polygon lazer tarayıcılar (SCANLAB 2019) ile kat kat daha da arttırılmaya çalışılmaktadır.

\subsection{Seçici Lazer Sinterleme (SLS) 3D Yazıcı Tasarım Aşamaları}

Literatür incelemelerinde metal AM (eklemeli imalat) sistemlerinde kullanılan teknolojiler, malzeme besleme şekli, enerji kaynağı ve imalat hacmine göre kategorize edilebilir. Tablo 1 bazı makine üreticileri ile bazı sistem özellikleri listelenmektedir (Herderick 2011). Bu tabloda üretim sistemi temel üç yönteme ayrılmıştır: (i) Toz Yatak Sistemi, (ii) Toz Besleme Sistemi, (iii) Tel Besleme Sistemi. Bu sistemler için enerji kaynağı (elektron 1şını (EBM), lazer, ark vb.) de belirtilmiştir.

Tablo 1 incelendiğinde üretim sisteminin temel üç yönteme ayrıldığı anlaşılmaktadır. Bu nedenle öncelikle toz yatak ve toz serme sisteminin tasarlanması gerektiği anlaşılmaktadır. Bu çalışmada yapılan çeşitli tasarımlar ve elde edilen veriler ile toz yatak ve toz serme sistemi tasarlanmıştır. Şekil 3 'de tasarlanan sistem gösterilmektedir.

Tablo 1. AM Ekipmanlarl ve Özellikleri

\begin{tabular}{|c|c|c|c|}
\hline Sistem & Proses & Yap1 Hacmi & Enerji Kaynağ 1 \\
\hline ARCAM & EBM & $200 \times 300 \times 350$ & $7 \mathrm{kw}$ elektron 1şın \\
\hline EOS & DMLS & $250 \times 250 \times 325$ & $\begin{array}{l}200-400 \mathrm{~W} \text { Yb-fiber } \\
\text { lazer }\end{array}$ \\
\hline $\begin{array}{l}\text { Consept } \\
\text { Laser } \\
\text { Cusing } \\
\end{array}$ & SLS & $300 \times 350 \times 300$ & $200 \mathrm{~W}$ fiber lazer \\
\hline MIT & SLS & $250 \times 250 \times 300$ & $\begin{array}{l}100-400 \mathrm{~W} \text { Yb-fiber } \\
\text { lazer }\end{array}$ \\
\hline $\begin{array}{l}\text { Phenix } \\
\text { System } \\
\text { Group }\end{array}$ & SLS & $250 \times 250 \times 300$ & $500 \mathrm{~W}$ fiber lazer \\
\hline Renishow & SLS & $245 \times 245 \times 360$ & $\begin{array}{l}200 \text { yada } 400 \mathrm{~W} \\
\text { lazer }\end{array}$ \\
\hline Realizer & SLS & $250 \times 250 \times 220$ & $\begin{array}{l}100,200 \text { yada } 400 \\
\text { W fiber lazer }\end{array}$ \\
\hline Matsuura & SLS & 250X250 Çaç & $\begin{array}{l}400 \mathrm{~W} \text { Yb fiber } \\
\text { lazer }\end{array}$ \\
\hline
\end{tabular}

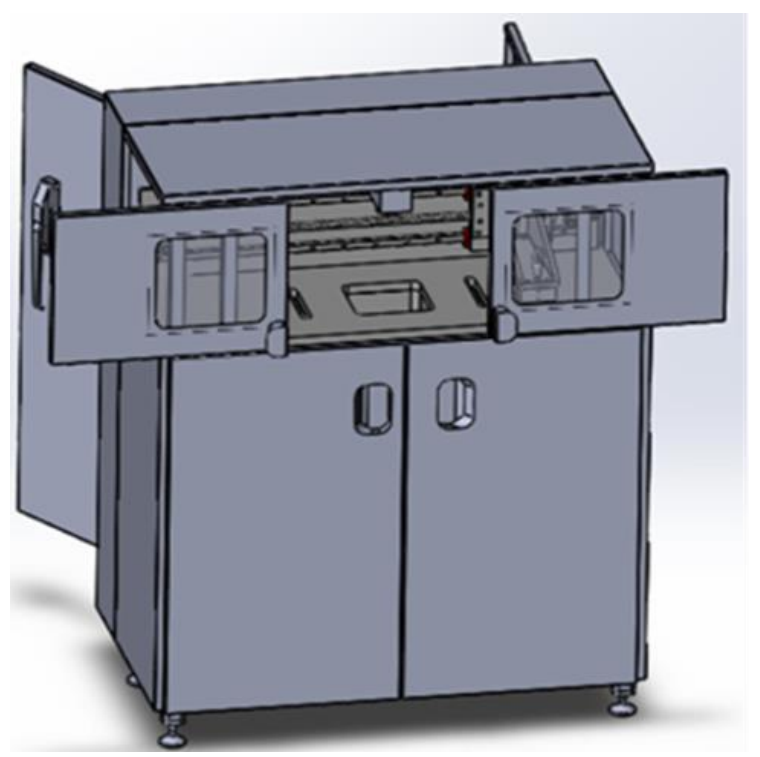

Şekil 3. 3D Toz Yatak Besleme ve Sürme Sistemi

Sistem temelde 4 bölümden oluşmaktadır. Lazer kaynağı, lazer ışınını yönlendirecek galvo kafa, toz besleme ve toplama sistemi, toz sürme mekanizmasıdır. Lazer kaynağı ve Galvo kafa piyasadan hazır elde edilebilen bileşen iken toz besleme ve toplama sisteminin tasarımı bu araştırmanın konusudur. Şekil 4'de tasarlanan sistemin giydirme sacları olmaksınız montajı görülmektedir.

Sistem temelde üç ana işlem basamağından oluşmaktadır.

1. Metal toz haznesinden tozun tabla üzerine istenilen miktarda beslenmesi. 
2. Beslenen tozun proses tablası üzerine katman kalınlığı kadar serilmesi.

3. Proses tablasının her yazım işlemi sonunda bir katman kalınlığı kadar aşă̆ı hareketidir.

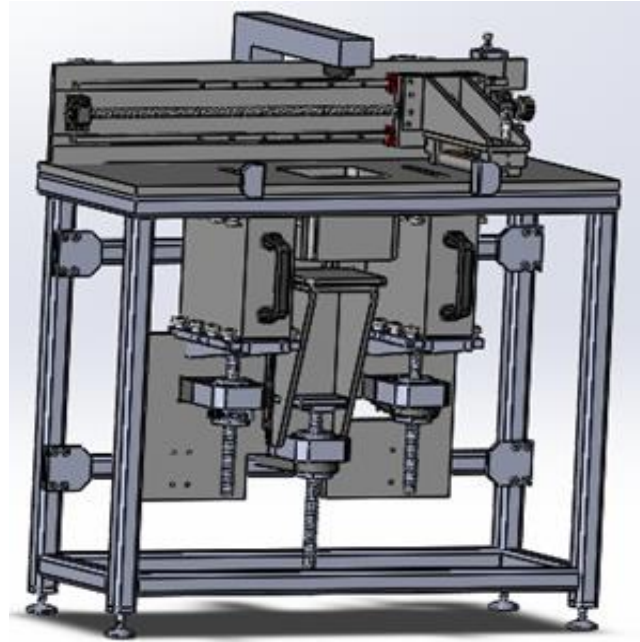

Şekil 4. Toz Besleme ve Sürme Detay Tasarım

$\mathrm{Bu}$ üç proses için de farklı mekanizmalar ve sistemler tasarlanmış ve entegrasyonu yapılarak bir montaj altında toplanmıştır. Şekil 5'de toz sürme sistemi ve ana tabla detayları gösterilmektedir.

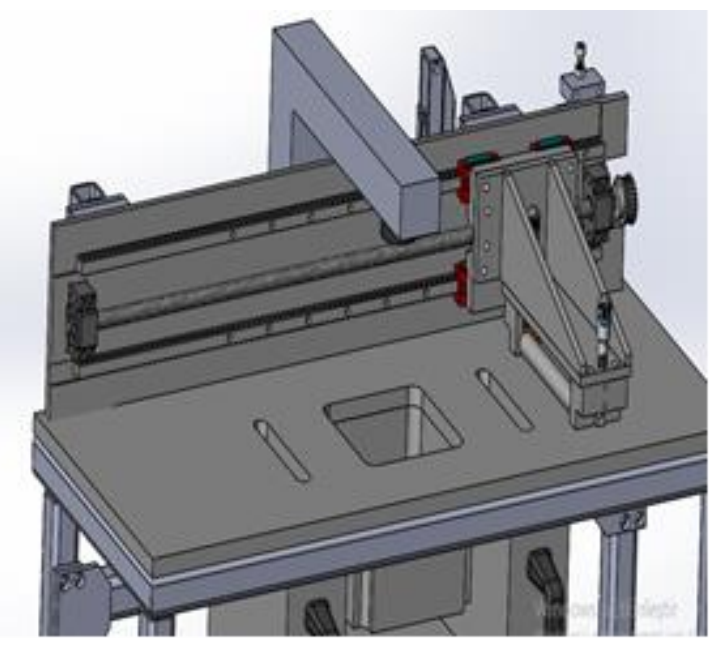

Şekil 5. Toz Sürme ve Ana Tabla Detayl

Tabla üzerinde toz besleme, proses tabla alanı ve fazla tozun boşaltıldığı kanallar bulunmaktadır. Toz besleme mekanizması ise vidalı mil, somun ve servo motor ile tahrik edilen bir mekanizmadır. Yataklamalar lineer kızak arabalarla sağlanmıştır. Tozun düzlemsel olarak sürülebilmesi için süpürgeler metal aşınmasını önlemek amacıyla krom kaplı indüksiyonlu merdaneler tarafindan yapılacaktır.

\subsection{Deney Cihazı Kurulumu ve Ön Deneyler}

Tasarım çalışmasının yürütülmesi için ön deneyler ve tasarım çalışmaları eş zamanlı olarak yapılmıştır. Tasarım esnasında belirsizliklerin daha da netleştirilmesi amaçlanarak eş zamanlı deney tesisatı kurulumu ve bazı parçaların imalatı gerçekleştirilmiştir. Bu amaçla ön çalışmalarda metal bronz tozu ile küçük parça üretimleri denenmiş ve elde edilen veriler ile toz yatak ve toz serme sistemi tasarlanmıştır. Gerçekleştirilen ön çalışmaların detayları aşağıda açıklanmıştır.

SLS 3D sistemi için önemli olan galvo ve kişiselleştirilmiş ara yüzün performansı için metal tozları üzerinde denemeler yapılmıştır. Bronz metal tozu $(45 \mu \mathrm{m})$ ve krom kobalt alaşım (30 $\mu \mathrm{m})$ tozu ile denemeler yapılmıştır.

$\mathrm{Bu}$ çalışmalar için deney teçhizatı kurulumu yapılarak, mevcuttaki $20 \mathrm{~W}$ lazer markalama tezgahının alaşımlar üzerindeki etkileri gözlemlenmiştir. Buna göre yukarıdaki 3 temel aşama takip edilerek aşağıdaki sonuçlar elde edilmiştir. Araştırmadaki ön denemelerde $20 \mathrm{~W} \mathrm{CO}_{2}$ lazer ile metal ergitme ve toz metalin birleştirilmesi için çalışmalar yapılmıştır.

Denemeler için krom kobalt alaşım $(30 \mu \mathrm{m})$ tozunu, ahşap bir havuza sererek üzerinde tam güçle 10 x $10 \mathrm{~mm}^{2}$ markalama işlemi gerçekleştirilmiştir. Tezgahla ilgili net bilgi olmadığı için, lazerin kesme kalitesine bakıldığında sabit odağın yaklaşık $21 \mathrm{~mm}$ değerinde olduğu tespit edilmiştir. Bu durumda ahşap havuz içerisinde $20 \mathrm{~W}$ güçte 2 defa tekrarlanan işlemde lazerin etkisiyle, neredeyse tozları birleştirdiği (Şekil 6 (b), 10x10 mm blok) gözlemlenmiştir.

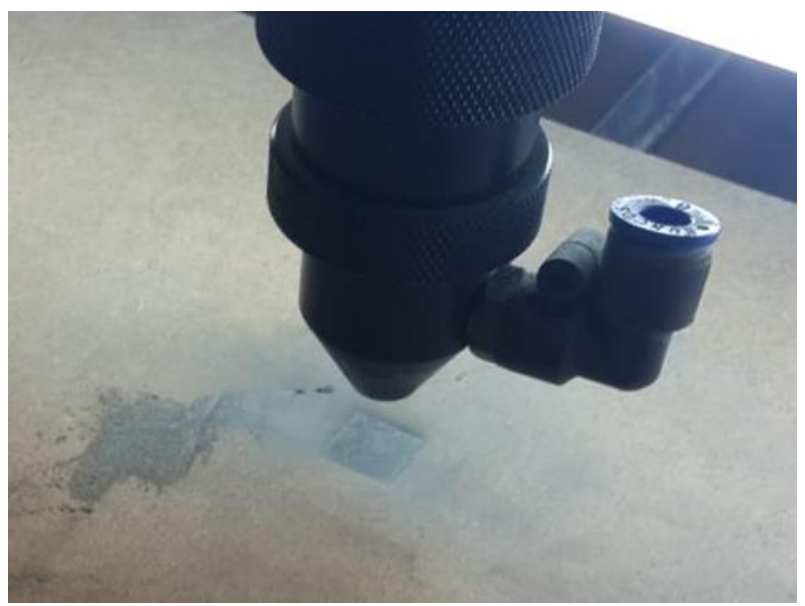

a)Lazer Başlı̆̆g

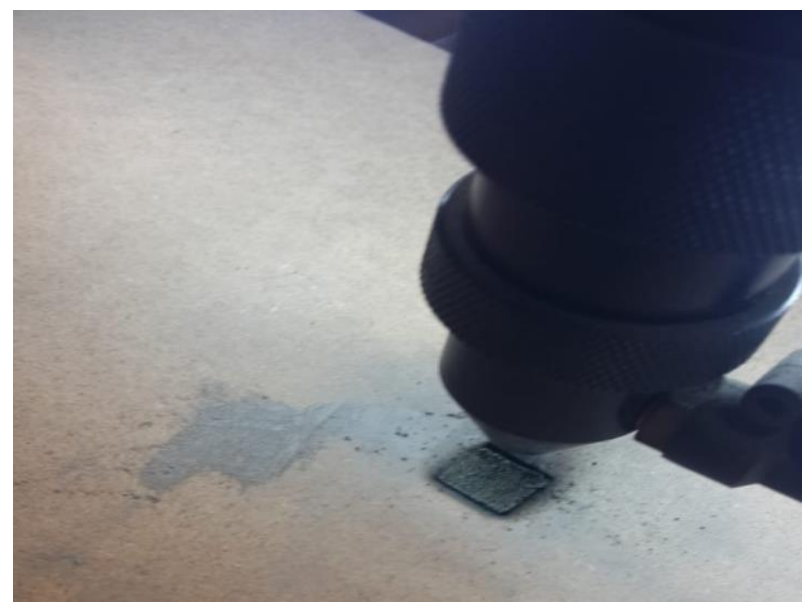

b)Lazer ile birleşen blok

Şekil 6. Ahşap Havuz Iç̧inde Alaşım Tozu ve Blok Numune 
Krom kobalt alaşım $(30 \mu \mathrm{m})$ tozu ile alınan sonuçtan hareketle, hafif metaller üzerinde daha iyi bir etki bırakılacağ düşünülerek, $20 \mathrm{~W}$ lazer gücünün performansını gösteren daha iyi bir deneysel kurulum hazırlanmıştır. Buna göre, katman kalınlığ alüminyum bir toz yatağı sistemi üretilmiştir. Şekil 7' de görülen bu fikstür ana gövde, hareketli inşa tablası, mikrometre ve fikstür bağlantı kulaklarından oluşmaktadır.

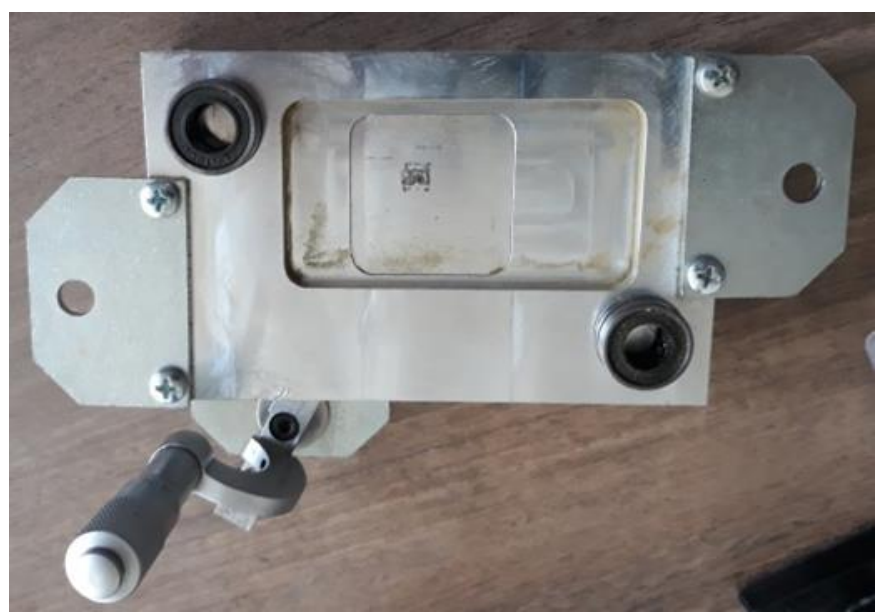

Şekil 7. Ön Denemelerde Kullanılan 3D Metal Baskı İçin Hazırlanan Manuel Toz Yată̆

Toz taneleri uzaklaştırıldığında yazılmaya çalışılan parça toz kümesi içerisinde belirmiştir. Parça ergiyerek birleştiği için alüminyum alt tablaya da yapışmıştır. El aleti kullanılarak parça tabladan ayrılmıştır. İki farklı deneme yapılarak iki farklı parça üretilmiştir. Şekil 8'de görüldüğü gibi parçalar tozun maliyeti ve 3 boyutlu lazer odaklamanın yapılamaması nedeni ile mümkün olduğunca küçük $1 \mathrm{~cm}$ boy ebatlarında üretilmiştir.

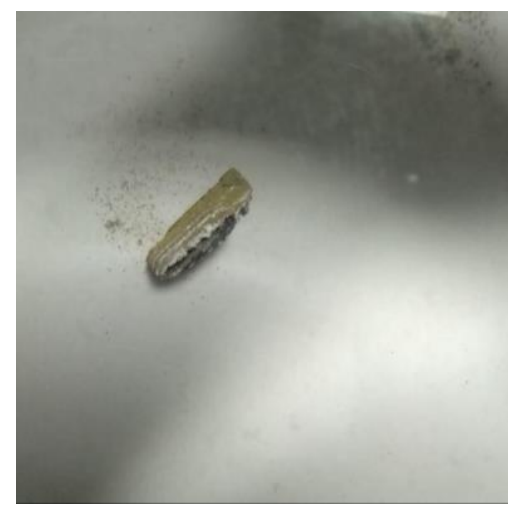

Şekil 8. 3D Baskı Denemesi Sonucunda Elde Edilen Parça

\section{Araştırma Sonuçları ve Tartışma}

Elde edilen veriler ile yukarda detayları belirtilen toz yatak ve toz serme sistemi tasarlanmıştır. Bu çalışmada Seçici Lazer Sinterleme (SLS) 3D yazıcı tasarımı aşağıda sıralanan temel aşamalar ile gerçekleştirilebileceği anlaşılmıştır.

1.Tasarlanan 3D CAD modelin, STL mesh yapısına çevrilmesi.

2.Mesh yapısının toz katman kalınlığına göre dilimlenmesi ve kesit alanın oluşturulması
3.Lazer spot çapına göre takım yolunun seçici lazer alanının belirlenmesi (Gcode oluşturulması)

4.Her bir kesit için oluşturulan $\mathrm{G}$ code için kontrol sisteminini (galvo kontrol kartının) lazeri doğru konumlamasının sağlanması, kontrol kartı ve galvo arasındaki iletişim protokolünün adaptasyonu ayarlanması.

5.Galvo sistemin kalibrasyonu ve doğruluk testleri için lazer marker noktaları oluşturulması, yakılan/çizilen konturların görüntü işleme yazılımları ile geometrik doğruluğunun ölçülmesi.

\section{Sonuç}

Eklemeli imalat süreci yüksek düzeyde karmaşıklık içermektedir. Bu süreç içerisindeki mekanizmalar literatürdeki çalışmaların konusu olmaya devam etmektedir. Metal parçaların $\mathrm{AM}$ ile üretiminde bu kısitlamalardan dolayı imalat endüstrisi tam anlamıyla AM yöntemi ile imalata geçiş yapamamıştır. Eklemeli imalat yöntemi ile ilgili simülasyon, modelleme çalışmaları literatüründe seçici lazer sinterleme (SLS) ve seçici lazer eritme (SLM) yöntemleri için termal analizler bulunmaktadır.

Özel geometrilere sahip hassas parçaların ekonomik, hızlı ve az adetli üretimi için bir çözüm avantajına sahip SLS tabanlı 3D yazıcıların geliştirilmesi önem arz etmektedir. $\mathrm{Bu}$ sistem tasarımı için yapılan araştırmaların üretim için simülasyon ve modelleme çalışmalarına göre daha az sayıda olduğu göze çarpmaktadır. Seçici Lazer Sinterleme (SLS) veya Eritme (SLM) tabanlı metal 3D yazıcı geliştirilmesi sürecinde sistem tasarımlarının geliştirilmesine ihtiyaç duyulmaktadır.

Araştırma konusunun yeni bir konu olması ve konuyla ilgili yapılan çalışmanın ülkemizde diğer araştırmacılara katkı sağlaması açısından önem taşımaktadır. Yapılan çalışmaların az olması nedeniyle elde edilecek bilgi birikiminin imalat sanayisine uygulanabilir olması da oldukça önemlidir.

Verimli bir SLS tabanlı 3D yazıcı sisteminde öncelikli olarak toz yatak ve toz serme sisteminin tasarlanması gerektiği anlaşılmaktadır.

\section{Kaynakça}

Berman, B.,(2012), "3-D printing, The new industrial revolution", Business Horizons, Vol. 55, No.2, p. 155-162.

Conner, B.P., et al., (2014), “ Making sense of 3-D printing: Creating a map of additive manufacturing products and services", Additive Manufacturing, Vol.1-4, p. 64-76.

Dong, L., et al.,(2020), "Three-dimensional transient finite element analysis of the selective laser sintering process", Journal of Materials Processing Technology, Vol.209, No.2, p. 700-706.

Herderick, E. ,(2011), “Additive manufacturing of metals: A review", Material Science and Technology, Vol 2, p.14131425.

Kathuria, Y.P., (1999), "Microstructuring by selective laser sintering of metallic powder", Surface and Coatings Technology, Vol.116, p. 643-647.

SCANLAB website [Online]. (2019) Available https://www.scanlab.de/en/products/advanced-scanningsolutions/polygon-scanner-systems.

Wong, K.V., Hernandez, A., (2012), “A Review of Additive Manufacturing”, ISRN Mechanical Engineering, p. 1-10. 